\title{
Pengembangan Kinerja UKM: Penggunaan Platform Digital dengan Kemampuan Jaringan dan Ambidexterity
}

\author{
(SME's Performance Development: Using of Digital Platform with \\ Network Capability and Ambidexterity)
}

Oleh:

Dian Rachmawati Afandi'), Maha Putra2)

Universitas Pelita Bangsa1,2)

dian.afandi@pelitabangsa.ac.id11), Maha36953@gmail.com ${ }^{2)}$

Submit: 24 Aug 2020

Review: 25 Aug 2020

Accept: 25 Aug 2020

Publish: 26 Aug 2020

\begin{abstract}
ABSTRAK
Perubahan dalam dunia bisnis di era digital tidak bisa dihindari sejalan dengan cepatnya perkembangan teknologi informasi komunikasi sehingga memaksa setiap orang harus cepat beradaptasi dan belajar lebih banyak mengenai perubahan ini. Hal ini menimbulkan persaingan yang ketat digitalisasi berbasis platform dan memberikan peluang bagi pelaku usaha untuk cepat berinteraksi baik secara internal maupun eksternal dimana hal ini belum pernah terjadi sebelumnya. Kekuatan kemampuan Studi ini meneliti pengaruh Platform Digital, Kemampuan Jaringan, dan Ambidexterity terhadap Kinerja UKM. Penelitian yang digunakan adalah penelitian asosiatif-kausal dengan pendekatan kuantitatif. Berdasarkan analisis atas 100 UKM kewirausahaan, hasilnya menunjukkan bahwa kemampuan platform digital memiliki efek positif langsung pada kinerja UKM.
\end{abstract}

Kata kunci:

Digitalisasi; Kapabilitas Jaringan; Ambidexterity, Kinerja UKM

\section{ABSTRACT}

Changes in the business world in the digital age can not be avoided in line with the rapid development of information communication technology that forces everyone to quickly adapt and learn more about these changes. This gives rise to fierce competition based on platform-based digitalization and provides opportunities for business players to quickly interact both internally and externally where this has never happened before. This study investigates the effect of Digital Platform, Network Capability, and Ambidexterity on SME's Performance. The research used is associative-causal research with a quantitative approach. The results indicate that digital platform, network capability, and Ambidexterity have a positive effect on entrepreneurial SME's performance.

Keywords:

Digital Platform, Network Capability, Ambidexterity SME's Performance. 


\section{PENDAHULUAN}

Saat ini informasi bukanlah hal yang sulit untuk diperoleh dan bukan menjadi sesuatu yang bernilai tinggi. Informasi merupakan kekuatan yang sangat luar biasa ditambah dengan kemampuan teknologi dan jaringan yang sangat luas. Kombinasi teknologi dan jaringan ini membuat seseorang memiliki potensi efektif pengembangan pengetahuan dalam memperoleh informasi.

Usaha kecil dan menengah (UKM) yakni suatu industri yang dapat meningkatkan perekonomian di Indonesia. Pertumbuhan UKM di Indonesia yang semakin bertambah jumlahnya dan belum sejajar dengan kenaikan kualitas UKM yang memadai. Masih melimpahnya persoalan yang dihadapi oleh UKM sehingga menyebabkan kapabilitas UKM untuk bergerak dalam perekonomian nasional tidak dapat maksimal. Saat ini pengembangan UKM sangat penting, dan saat ini UKM juga mendapatkan perhatian penuh dari masyarakat maupun pemerintah untuk bisa bersaing secara kompetitif dengan pelaku bisnis lainnya (Arfanly and Syamsun, 2017).

Perkembangan UKM di Indonesia menuntut para pelaku usaha untuk terus melakukan inovasi agar mampu bersaing baik secara nasional maupun internasional. Hal inilah harusnya yang memacu munculnya usaha-usaha baru tentunya dengan kinerja yang baik. Kebanyakan para UKM cenderung kurang memiliki pengetahuan yang luas dan orientasi terhadap usaha secara jangka panjang. Kendala yang dihadapi UKM misalnya dalam hal porduksi dan pengolahan, pemasaran, sumber daya manusia, desain dan teknologi, permodalan, serta iklim usaha.

Dalam pencapaian tujuan sebuah organisasi maka keberhasilan usaha dapat dilihat dari kinerja. Untuk dapat melihat kinerja organisasi maka dapat dilihat sejauh mana tujuan strategis organisasi, kepuasan konsumen dapat memberikan pemasukan lebih secara ekonomi telah tercapai. Sehingga kita dapat memberikan penjelasan kinerja sebagai pelaksanaan sebuah pekerjaan kemudian melihat hasil yang dicapai dan bagaimana melaksanakan pekerjaan tersebut. Oleh karena itu penjualan berbasis teknologi, dalam bentuk media sosial, telah digunakan oleh organisasi untuk meningkatkan kinerja penjualan (Panagopoulos 2010)

Menanggapi tekanan kompetitif, banyak dari UKM kewirausahaan menggunakan platform digital untuk meningkatkan strategi bisnis mereka. Platform digital adalah teknologi yang memungkinkan perusahaan untuk menyeragamkan, mengedit, dan mendistribusikan data pada skala yang belum pernah terjadi sebelumnya. Misalnya, perangkat dan perangkat lunak baru (misalnya, mesin canggih) dan standar jaringan (misalnya, protokol peerto-peer) memungkinkan fitur baru muncul. Platform digital dengan demikian mengubah cara perusahaan membangun keunggulan kompetitif . Bahkan, platform digital memainkan peran sentral dalam proposisi nilai banyak perusahaan dengan memungkinkan mereka untuk meningkatkan manajemen informasi (Cenamor, Rönnberg Sjödin, \& Parida, 2017). Misalnya, data besar, kecerdasan buatan, dan pembelajaran mesin telah menjadi prioritas bagi banyak perusahaan yang bersaing dalam ekosistem platform digital ( Subramaniam, Iyer, \& Venkatraman, 2018 ).

Teknologi digital didasarkan pada sistem TIK yang menstandarkan informasi dan memungkinkan organisasi untuk 
dengan cepat mengkode, menyimpan, memformalkan, dan mendistribusikan pengetahuan yang semakin banyak jumlahnya, yang semakin beragam. Selama dua dekade, penelitian telah meneliti bagaimana teknologi TIK dan digital dapat meningkatkan kinerja keseluruhan melalui peningkatan efisiensi operasional (misalnya, melalui manajemen persediaan yang lebih baik) dan orientasi pelanggan (misalnya, melalui pencocokan kebutuhan pasar yang lebih akurat. Dalam konteks ini, perkembangan teknis telah menyebabkan munculnya dan penyebaran cepat teknologi yang lebih kompleks, yang dikenal sebagai platform digital ( Parker et al., 2016 ).

Pentingnya digitalisasi telah meningkat. Setelah awalnya menjadi masalah teknis, digitalisasi kini telah menjadi masalah manajemen strategis yang mempengaruhi inti dari proposisi nilai. Meluasnya platform digital, fokus penciptaan nilai telah beralih dari rantai nilai linear tradisional ke jaringan yang saling terkait secara cepat dan mudah. Dalam Studi Mu (2014) yang dilakukan di salah satu perusahaan di Amerika, mendefinisikan kemampuan jaringan sebagai kemampuan perusahaan untuk menemukan mitra jaringan dan mengelola hubungan jaringan untuk menciptakan keunggulan kompetitif. pada dasarnya untuk dapat menemukan mitra jaringan mengacu pada kemampuan dalam memperluas pencarian yang dilakukan perusahaan untuk dapat mengidentifikasi individu atau organisasi yang tepat agar perusahaan dapat berinteraksi secara efektif (Mu 2014; Mu and Di Benedetto 2012).

Penelitian tentang kewirausahaan dan ambidexterity secara ekstensif menguji dua konsepsi yang berbeda dari orientasi organisasi - eksplorasi dan eksploitasi - dan implikasi kinerja yang sesuai . Di satu sisi, eksploitasi berfokus pada pengetahuan internal saat ini, kemampuan, dan pengambilan keputusan yang mapan untuk memaksimalkan keuntungan dari bisnis yang ada. Eksploitasi biasanya berkaitan dengan pendapatan yang dapat diandalkan, kontrol dan efisiensi tinggi, dan keberhasilan jangka pendek. Di sisi lain, eksplorasi berfokus pada mempelajari pengetahuan baru, menemukan kemampuan baru, dan menyelidiki caracara baru dalam berbisnis. Orientasi eksplorasi umumnya memiliki hubungan dengan hasil yang tidak pasti, otonomi tinggi, dan hasil jangka panjang. Orientasi ini tentu dapat memengaruhi profitabilitas platform digital karena teknologi yang diadopsi harus konsisten dengan nilai-nilai UKM .

Jabodetabek adalah sebuah Akronim dari Jakarta , Bogor, Depok ,Tangerang dan Bekasi yaitu sebuah kawasan megapolitan yang menjadi penopang ekonomi Negara saat ini, Salah satunya yang paling memberi dampak ekonomi yang besar adalah Bekasi. Dengan puluhan ribu penduduknya mereka secara bersamasama membentuk kawasan-kawasan megapolitan. Di bekasi sendiri terdapat daerah yang menjadi pusat perindustrian terbesar di Asia Tenggara yaitu Cikarang. Tak heran pada tahun 2017 cikarang telah menjadi salah satu pusat industry nasional dengan jumlah penanaman modal asing mencapai $34,46 \%$ dan volume ekspor sebesar 22-45 \% . (BPS.go 2017)

Tercatat ada beberapa Kawasan industry sudah berada di Cikarang, antara lain EJIP,MM2100, Jababeka 1, jababeka 2 Delta Silicon 1, delta silicon 2, dan GIIC. Keberdaan kawasan industry ini tentu memberikan dampak yang positif umumnya kepada Negara dan masyarakat. beberapa diantaranya yaitu terbukanya 
lapangan pekerjaan ,dan munculnya berbagai peluang usaha baru. Salah daerah satu yang mendapat dampaknya yaitu Kampung kukun.

Kampung Kukun adalah salah satu dusun yang terletak di desa Ciantra kecamatan Cikarang Selatan. Ratusan perusahaan nasional maupun multinasional dengan jumlah pekerja yang mencapai ratusan ribu jiwa yang ada di sini menimbulkan lahirnya ribuan unit usaha atau UKM . Mayoritas para pelaku usaha di kampung kukun berasal dari luar cikarang yang pernah bekerja di salah satu perusahan yang kemudian menetap dan berumah tangga disini. Kebanyakan UKM yang timbul disini adalah kinerja UKM yang tidak stabil. Minimnya pengetahuan, manajemen keuangan yang buruk dan kurang mampunya bersaing membuat banyak dari para UKM yang kehabisan modal dan tidak melanjutkan lagi usahanya. Banyaknya UKM yang ada di cikarang khususnya kampung kukun membuat persaingan yang tak terhindarkan. Di tengah era digital para UKM dituntuk untuk terus melakukan inovasi salah satunya yaitu dengan penggunaan Platform Digital, namun banyak dari UKM yang belum mengetahui tentang penggunaan Platform digital maka tak heran masih banyak UKM yang bertahan dengan system konvensional.

Untuk mengatasi masalah tersebut maka diperlukannya kemampuan jaringan. Dengan mengacu pada koordinasi anatara kelompok dan individu memungkinkan terjadinya komunikasi internal dari pengetahuan eksternal, keterampilan relasional untuk menangani beragam individu dan pengetahuan mitra. Singkatnya, penelitian ini ingin mengetahui sejauh mana kinerja UKM dengan adanya kemampuan jaringan mewakili kemampuan kunci dalam perusahaan digital ditambah dengan pendekatan Amdidexterity.

\section{METODE PENELITIAN}

\section{Jenis Penelitian}

Penelitian menggunakan pendekatan asosiatif-kausal. Pemilihan pendekatan ini dimaksudkan untuk mengetahui hubungan antara dua variable atau lebih yang bersifat hubungan sebab-akibat antara variabel Platform Digital, Kemampuan Jaringan, Ambidexterity dan kinerja UKM dengan menggunakan data primer sebagai sumber data.

\section{Pengumpulan Data}

Pengumpulan data menggunakan kuesioner dan observasi. Kuesioner yang digunakan dalam penelitian ini adalah kuesioner terbuka, selanjutnya kuesioner penelitian dibagi menjadi dua bagian. Bagian pertama berisi data karakteristik responden yang terdiri dari nama, umur, jenis kelamin, nama usaha, jabatan, dan pendidikan terakhir. Bagian kedua berisi pertanyaan yang berhubungan dengan variabel independen dan variabel dependen.

Tabel 1

Indikator Penelitian

\begin{tabular}{|c|c|c|}
\hline Variab & Indikator & Referensi \\
\hline $\begin{array}{l}\text { Platform } \\
\text { Digital }\end{array}$ & $\begin{array}{l}\text { a. Integrasi } \\
\text { b. Rekonfigurasi }\end{array}$ & $\begin{array}{l}\text { Rai \& Tang } \\
\text { (2010) }\end{array}$ \\
\hline $\begin{array}{l}\text { Kemam- } \\
\text { puan } \\
\text { Jaringan }\end{array}$ & $\begin{array}{l}\text { a. Koordinasi } \\
\text { b. Keterampilan } \\
\text { hubungan } \\
\text { c. Pengetahuan mitra } \\
\text { d. Komunikasi internal }\end{array}$ & Walter (2006) \\
\hline $\begin{array}{l}\text { Ambidex } \\
\text {-terity }\end{array}$ & $\begin{array}{l}\text { a. eksploitasi } \\
\text { b. eksplorasi }\end{array}$ & $\begin{array}{l}\text { Kristal et } \\
\text { al.,2010 }\end{array}$ \\
\hline $\begin{array}{l}\text { Kinerja } \\
\text { UKM }\end{array}$ & $\begin{array}{l}\text { a. Keuangan } \\
\text { b. Operasional }\end{array}$ & $\begin{array}{c}\text { Santos \& } \\
\text { Brito (2014) }\end{array}$ \\
\hline
\end{tabular}


Observasi dilakukan dengan pengamatan secara sistematis terhadap gejala yang ada pada lokasi penelitian. Pengamatan dilakukan bertempat di Kampung Kukun Kec. Cikarang Selatan. Kemudian studi kepustakaan dilakukan dengan cara mengumpulkan artikelartikel, teori yang relevan, dan literature lainnya yang ada kaitannya dengan penelitian ini berdasarkan penelitianpenalitian terdahulu dan berdasarkan jurnal-jurnal internasional serta di dukung jurnal nasional.

\section{Populasi dan Sampel}

Populasi yang digunakan dalam penelitian ini adalah UKM yang berada di kampung kukun sebanyak 100 UKM. Sampel tersebut yang diambil dari populasi harus betul-betul representatif (mewakili) (Sugiyono, 2010: 118). Dalam penelitian ini teknik yang digunakan adalah purposive sampling yaitu memilih sampel dengan sengaja namun dengan pertimbangan tertentu dengan jumlah 50 UKM.

\section{Metode Analisis Data}

Metode analisis digunakan untuk menginterprestasikan dan menganalisis data. Analisis didahui dengan uji instrumen yang terdiri dari: Uji Validitas dan Uji Reliabilitas. Analisis dilanjutkan dengan analisis regresi linier ganda berturut-turut: Uji Asumsi Klasik: Uji Normalitas, Uji Multikolinearitas, Uji Heteroskedasitas; Uji Model: Analisis Koefisien Determinasi dan Uji-F; Uji Hipotesis: Model Persamaan Regresi Linier Ganda dan uji-t.

Uji normalitas digunakan untuk menguji apakah data yang bersangkutan berdistribusi normal atau tidak. Uji normalitas dilakukan dengan menggunakan uji Kolmogorov-Smirnov.
Dimana data dapat dikatakan berdistribusi normal jika nilai Asymp. Sig (2-tailed) $\geq$ 0,05 maka data berdistribusi normal, jika nilai Asymp. Sig (2-tailed) < 0,05 maka data berdistribusi tidak normal (Ali Muhson, 2012:21).

Alat statistik yang digunakan menguji gangguan multikolinearitas adalah nilai independen dan variance inflation factor (VIF). Apabila nilai tolerance $>0,1$ dan nilai VIF $<10$, maka tidak terjadi multikolinearitas.

Menguji ada tidaknya heteroskedastisitas dalam model regresi digunakan analisis dengan uji glesjer (Imam Ghozali, 2006). Kriteria pengambilan keputusan adalah signifikansi variabel bebas lebih besar dari 0,05 maka tidak terjadi heterokedastisitas.

Pengujian model dilakukan dengan koefisien determinasi $\left(\mathrm{R}^{2}\right)$ yaitu untuk mengukur seberapa jauh kemampuan model regresi dalam menerangkan variasi variabel dependen (Ghozali, 2012). Adjusted $\mathrm{R}^{2}$ atau koefisien determinasi $\left(\mathrm{R}^{2}\right)$ mempunyai nilai berkisar antara $0<\mathrm{R}^{2}<1$. Nilai Adjusted $\left(\mathrm{R}^{2}\right)$ yang kecil berarti kemampuan variasi variabel dependen terbatas. Jika nilai mendekati satu maka variabel-variabel independen memberikan hampir semua informasi yang dibutuhkan untuk memprediksi variasi variabel dependen. Pengujian model yaitu terhadap koefisien determinasi menggunakan uji-F.

Persamaan regresi linier ganda merupakan model yang digunakan untuk menguji hipotesis pengaruh platform digital, kapabilitas jaringan dan ambidexterity terhadap kinerja UKM. Nilai yang diuji adalah koefisien prediktor ( $b 1$, $b 2$ dan $b 3$ ) berdasar persamaan regresi linier ganda:

$\mathrm{Y}=\mathrm{a}+\mathrm{b} 1 \mathrm{X} 1+\mathrm{b} 2 \mathrm{X} 2+\mathrm{b} 3 \mathrm{X} 3 \ldots \ldots \ldots \ldots \ldots 1)$

Pengujian hipotesis dilakukan dengan ujit. Hipotesis diterima jika nilai sig. $<\alpha$. 
HASIL PENELITIAN

\section{Uji Persyaratan Analisis}

Uji persyaratan analisis diawali dengan uji normalitas. Hasil dari pengujian normalitas disajikan pada tabel 2 .

Tabel 2

Hasil Uji Normalitas

\begin{tabular}{|c|c|c|}
\hline Variabel & $\begin{array}{c}\text { Asymp. Sig. } \\
\text { (2-tailed) }\end{array}$ & $\begin{array}{c}\text { Keteranga } \\
n\end{array}$ \\
\hline $\begin{array}{l}\text { Platform Digital, } \\
\text { kemampuan } \\
\text { Jaringan, } \\
\text { Ambidexterity, } \\
\text { dan Kinerja UKM }\end{array}$ & 0,200 & $\begin{array}{l}\text { Data } \\
\text { terdistribu } \\
\text { si Normal }\end{array}$ \\
\hline
\end{tabular}

Sumber: Data penelitian yang diolah, 2020

Tabel 2 menghasilkan Asymp. Sig (2tailed) untuk semua variabel tidak ada yang menunjukkan nilai kurang dari 0.05 yang berarti semua data berdistribusi normal.

Hasil uji prasyarat multikolinearitas dapat dilihat pada tabel 3:

Tabel 3

Hasil Uji Multikolinearitas

\begin{tabular}{lc}
\hline \multicolumn{1}{c}{ Variabel } & VIF \\
\hline Platform Digital (X1) & 1.012 \\
Kemampuan Jaringan (X2) & 1.279 \\
Ambidexterity (X3) & 1.280 \\
\hline
\end{tabular}

Sumber: Data penelitian yang diolah, 2020

Tabel 3 menunjukkan bahwa variabel Platform Digital memiliki nilai VIF sebesar $1,055<10$ maka tidak terjadi multikolinearitas.Variabel Kemampuan Jaringan memiliki VIF sebesar 1,267 < 10 maka tidak terjadi multikolinearitas, dan Ambidexterity nilai VIF sebesar 1,273 < 10 maka tidak terjadi multikolinearitas. Dapat disimpulkan bahwa antara variable Platform digital, variabel kemampuan jaringan dan variabel ambidexterity tidak saling mempengaruhi atau tidak terjadi multikolinearitas.
Hasil pengujian heteroskedastisitas dapat dilihat dalam tabel berikut :

Tabel 4

Hasil Uji Heteroskedastisitas

\begin{tabular}{lc}
\hline \multicolumn{1}{c}{ Variabel } & Signifikansi \\
\hline Platform Digital (X1) & 0,452 \\
kemampuan Jaringan (X2) & 0,639 \\
Ambidexterity (X3) & 0,630 \\
\hline
\end{tabular}

Sumber: Data penelitian yang diolah, 2020

Tabel 4 menunjukkan bahwa variabel platform digital memiliki nilai Sig. sebesar 0,450 > 0,05 maka disimpulkan bahwa variabel tersebut memenuhi syarat tidak terjadi heterokedasitas. Variabel kemampuan jaringan diketahui memiliki nilai Sig. sebesar 0,171 > 0,05 maka disimpulkan bahwa variabel tersebut memenuhi syarat tidak terjadi heterokedasitas dan untuk variabel ambidexterity diketahui memiliki nilai Sig. sebesar 0,509 > 0,05 maka disimpulkan bahwa variabel tersebut memenuhi syarat tidak terjadi heterokedasitas. Kesimpulan akhir bahwa variabel platform digital, kemampuan jaringan, dan ambidexterity tidak terjadi heterokedastisitas.

\section{Uji Model}

Pengujian model didasarkan nilai koefisien determinasi dan nilai Sig. F. Nilai tersebut diperoleh dari rangkuman hasil analisis yang terdapat pada tabel 5 . Hasil uji Adjusted $\mathrm{R}^{2}$ pada penelitian ini diperoleh nilai Adjusted $\mathrm{R}^{2}$ sebesar 0,923 dengan nilai Sig. F sebesar 0.000 . Nilai tersebut cukup tinggi dan signifikan sehingga model persamaan regresi linier ganda hasil analisis layak digunakan untuk menjelaskan pengaruh variabel independen terhadap variabel dependen. Dapart diartikan bahwa variable Platform digital, variabel kemampuan jaringan dan variabel ambidexterity mampu menjelaskan 92,3\%, variasi kinerja UKM. 
Tabel 5

Hasil Uji Keofisien Determinasi Adjusted R²)

\begin{tabular}{lcccccc}
\hline Model & $\mathrm{R}$ & R Square & $\begin{array}{c}\text { Adjusted R } \\
\text { Square }\end{array}$ & $\begin{array}{c}\text { Std. Error of the } \\
\text { Estimate }\end{array}$ & $\begin{array}{c}\text { Durbin- } \\
\text { Watson }\end{array}$ & Sig. F \\
\hline 1 & $.963^{\mathrm{a}}$ & 0.928 & 0.923 & 0.897 & 1.764 & .000 \\
$\begin{array}{l}\text { a. Predictors: (Constant), X3, X1, X2 } \\
\text { b. Dependent Variabel: Y }\end{array}$ & & & & \\
\hline
\end{tabular}

Sumber: Data penelitian yang diolah, 2020

Uji Hipotesis

Pengujian hipotesis dilakukan menggunakan model persamaan regresi linier ganda dan uji-t. Uji hipotesis didasarkan pada hasil analisis yang dirangkum pada tabel 6 .

Tabel 6

Hasil Uji T

Coefficients ${ }^{a}$

\begin{tabular}{ccccccccc}
\hline \multirow{2}{*}{ Model } & \multicolumn{2}{c}{$\begin{array}{c}\text { Unstandardized } \\
\text { Coefficients }\end{array}$} & $\begin{array}{c}\text { Stad. } \\
\text { Coefficient }\end{array}$ & $\mathrm{t}$ & Sig. & \multicolumn{2}{c}{ Collinearity Statistics } \\
\cline { 2 - 4 } & $\mathrm{B}$ & Std. Error & Beta & & & & Tolerance & VIF \\
\hline (Constant) & 3.510 & 1.224 & & 2.869 & 0.006 & & \\
X1 & 0.254 & 0.027 & 0.381 & 9.553 & 0.000 & 0.988 & 1.012 \\
X2 & 0.246 & 0.039 & 0.285 & 6.367 & 0.000 & 0.782 & 1.279 \\
X3 & 0.383 & 0.024 & 0.729 & 16.266 & 0.000 & 0.782 & 1.280 \\
\hline
\end{tabular}

a. Dependent Variable: Y

Sumber: Data penelitian yang diolah, 2020

Dari tabel 6 dapat dibuat model persamaan regresi linier ganda sebagai berikut :

$Y=3,510+0,254 X 1+0,246 X 2+0,383 X 3$

Koefisien variabel platform digital dalam persamaan regresi berganda sebesar 0,254, koefisien regresi variabel kemampuan jaringan sebesar 0,246 dan koefisien regresi variabel ambidexterity sebesar 0,385. Uji $t$ pada dasarnya menunjukan seberapa jauh pengaruh satu variabel penjelasan atau independen secara individual dalam menerangkan variasi variabel dependen. Pengambilan keputusan ini dilakukan berdasarkan perbandingan nilai signifikansi dari nilai thitung masingmasing koefisien regresi dengan tingkat signifikansi thitung lebih besar dari 0,05, maka hipotesis nol (Ho) ditolak yang artinya variabel independen berpengaruh terhadap variabel dependen (Ghozali, 2016). Penjelasan untuk hasil uji $t$ pada masing-masing variabel independen adalah sebagai berikut :

Variabel Platform Digital (X1) memiliki nilai koefisien regresi $b 1=0,254$ dan tingkat signifikasi sebesar 0,000. Dari hasil uji $\mathrm{t}$ pada variabel Platform Digital 
(X1) menyatakan bahwa signifikansi uji $\mathrm{t}$ lebih kecil dari 0,05 dan koefisien regresi mempunyai nilai positif sebesar 0,254. Sedangkan nilai $\mathrm{t}$ hitung yang diperoleh yaitu 9,553 lebih besar dari t-tabel yaitu 1,984. Berdasarkan hasil tersebut maka hipotesis yang menyatakan "terdapat pengaruh positif secara parsial antara variabel bebas Platform Digital terhadap variabel terikat Kinerja UKM (Y) studi di UKM Kampung Kukun cikarang selatan" terbukti atau diterima.

Variabel Kemampuan Jaringan (X2) memiliki nilai koefisien regresi b2 - 0,246 dan tingkat signifikasi sebesar 0,000. Dari hasil uji $t$ pada variabel Kemampuan Jaringan (X2) menyatakan bahwa signifikansi uji t lebih kecil dari 0,05 dan koefisien regresi mempunyai nilai positif sebesar 0,246; sedangkan nilai $t$ hitung yang diperoleh yaitu 6,367 lebih besar dari t tabel yaitu 1,984. Berdasarkan hasil tersebut maka hipotesis yang menyatakan “terdapat pengaruh positif secara parsial antara variabel bebas Kemampuan Jaringan (X2) terhadap variabel terikat Keinerja UKM (Y) studi di UKM Kampung Kukun cikarang selatan" terbukti atau diterima.

Variabel Ambidexterity (X3) memiliki nilai koefisien regresi b3 - 0,383 dan tingkat signifikasi sebesar 0,000. Dari hasil uji $t$ pada variabel Ambidexterity (X3) menyatakan bahwa signifikansi uji $t$ lebih kecil dari 0,05 dan koefisien regresi mempunyai nilai positif sebesar 0,383. Sedangkan nilai $\mathrm{t}$ hitung yang diperoleh yaitu 16,266 lebih besar dari t tabel yaitu 1,984. Berdasarkan hasil tersebut maka hipotesis yang menyatakan "terdapat pengaruh positif secara parsial antara variabel bebas Ambidexterity terhadap variabel terikat Keinerja UKM (KU) studi di UKM Kampung Kukun cikarang selatan" terbukti dan diterima.

\section{PEMBAHASAN}

Model penelitian terbukti layak digunakan untuk menguji atau menganalisis pengaruh variabel platform digitas, kemampuan jaringan dan ambidexterity.

Pengaruh Platform Digital Terhadap Kinerja UKM

Variabel Platform digital dinyatakan memiliki pengaruh positif terhadap variabel kinerja UKM ditunjukan dengan nilai koefisien regresi sebesar 0,254. Dengan demikian dapat diketahui bahwa Kinerja UKM di Kampung Kukun dipengaruhi oleh Platform Digital.

Hasil penelitian ini sesuai dengan penelitian Javier Cenamur, Joakim, dan Vinit Parida (2019) yang menghasilkan kesimpulan bahwa terdapat pengaruh positif platform digital terhadap kinerja UKM. Hal ini semakin menunjukkan pentingnya membangun atau bekerjasama dengan platform digital khususnya dengan jalan meningkatkan integrasi dan rekonfigurasi.

\section{Pengaruh Kemampuan Jaringan Terhadap Kinerja UKM \\ Variabel Kemampuan Jaringan} dinyatakan memiliki pengaruh positif terhadap variabel Kinerja UKM ditunjukkan dengan nilai koefisien regresi sebesar 0,246. Dengan demikian dapat diketahui bahwa Kinerja UKM di Kampung Kukun dipengaruhi oleh Kemampuan Jaringan.

Hasil penelitian ini sesuai dengan penelitian Choirunnisa, Augusty Tae Ferdinand, Farida Indriani (2017) yang menghasilkan kesimpulan bahwa pemberdayaan masyarakat memiliki pengaruh positif dalam meningkatkan kinerja UKM. Dengan kondisi ini memberi isyarat perlunya UKM meningkatkan kemampuan koordinasi, keterampilan 
menjalin hubungan, mengetahui mitra utamanya dan komunikasi internal.

\section{Pengaruh Ambidexterity Terhadap Kinerja UKM}

Variabel Ambidexterity dinyatakan memiliki pengaruh positif terhadap variabel Kinerja UKM ditunjukkan dengan nilai koefisien regresi sebesar 0,383. Dengan demikian dapat diketahui bahwa Kinerja UKM di Kampung Kukun dipengaruhi oleh Kemampuan Jaringan.

Hasil penelitian ini sesuai dengan penelitian Javier Cenamur, Joakim, dan Vinit Parida (2019) yang menghasilkan kesimpulan bahwa tetrdapat pengaruh positif Ambidexterity terhadap kinerja UKM. Oleh karena itu diharapkan agar UKM meningkatkan ketangkasan kesigapan dengan mengedepankan pada orientasi eksploitasi dan eksplorasi.

\section{KESIMPULAN}

Platform Digital berpengaruh positif terhadap Kinerja UKM di Kampung Kukun sebesar 0,254. Kemampuan jaringan berpengaruh positif terhadap Kinerja UKM di Kampung Kukun sebesar 0,246. Ambidexterity berpengaruh positif terhadap Kinerja UKM di Kampung Kukun sebesar 0,383.

UKM hendaknya terus meningkatkan kemampuan dan pengetahuan tentang penggunaan Platform Digital, memperluas jaringan usaha dan mengembangkan potensi secara maksimal di imbangi dengan terus mencari peluang baru.

Diharapkan ada penelitian lanjutan tentang Platform Digital, Kemampuan Jaringan, Ambidexterity dan Kinerja UKM dengan lebih baik dan menyempurnakan hasil penelitian ini atau menambahkan variabel lain yang sesuai atau yang berkaitan.

\section{PUSTAKA}

Ali Muhson. 2012. Modul Pelatihan SPSS. Diktat UNY

Arfanly, Bibi, Ma'mun Sarma, And Muhammad Syamsun. (2016). Analisis Strategi Entrepreneurial Marketing Pada Industri Rumahan Kabupaten Kendal Serta Pengaruhnya Terhadap Kinerja Pemasaran, Bogor Agricultural University (IPB)

Cenamor, J., Rönnberg Sjödin, D., \& Parida, V. (2017). Adopting a platform approach in servitization: Leveraging the value of digitalization. International Journal of Production Economics, 192, 54-65

Choirunnisa, Augusty Tae Ferdinand, dan Farida IndrianiPurwanti, (2018). Analisis Pengaruh penginderaan pasar, pemasaran kewirausahaan, kemampuan jaringan dan keunggulan bersaing terhadap kinerja ( studi pada ukm makanan dan minuman ) Semarang : Jurnal Bisnis Strategi, vol. 27, no.2

Hagiu, A., \& Wright, J. (2018). Controlling vs. enabling. Management Science, 65(2), 577-595.

Hubeis, Musa. (2009). Prospek Usaha Kecil dalam Wadah Inkubator Bisnis. Bogor: Ghalia Indonesia.

Javier Cenamor., Vinit Parida ., \& Joakim Wincent .(2019). How entrepreneurial SMEs compete through digital Platform : The roles of digital platform capability, network capability , and ambidexterity. Findlan : jurnal of business research. Vol.100 196-206.

Kristal, M. M., Huang, X., \& Roth, A. V. (2010). The effect of an ambidextrous supply chain strategy on combinative competitive capabilities and business performance. Journal of Operations Management, 28(5), 415-429. 
Mu, Jifeng, And Anthony Di Benedetto. (2012). Networking Capability And New Product Development. IEEE Transactions On Engineering Management 59(1):4-19.

Panagopoulos, Nikolaos (2010), Sales Technology: Making the Most of Your Investment, New York: Business Expert.

Parker, G., Van Alstyne, M., \& Choudary, S. P. (2016). Platform revolution: How networked markets are transforming the economy and how to make them work for you (1st ed.). New York: W. W. Norton \& Company.

Rai, A., \& Tang, X. (2010). Leveraging IT capabilities and competitive process capabilities for the management of interorganizational relationship portfolios. Information Systems Research, 21(3), 516-542.

Santos, J. B. \& Brito, L. A. L. (2012). Toward a subjective measurement model for firm performance. Brazilian Administration Review (BAR), 9(6), 95-117. http://dx.doi.org/10.1590/S1807-76922012000500007

Subramaniam, M., Iyer, B., \& Venkatraman, V. (2018). Competing in digital ecosystems. Business Horizons.

Walter, Achim, Michael Auer, And Thomas Ritter. (2006). The Impact Of Network Capabilities And Entrepreneurial Orientation On University Spin-Off Performance. Journal of Business Venturing 21(4):541-567. 